\title{
Cultural Industry Cluster in Cultural Heritage Area: Case Study on the Pearl River Delta
}

\author{
Yu-Bin LUO',a \\ ${ }^{1}$ Department of Civil Engineering, Dongguan University of Technology, Dongguan, 523808, China \\ ånolandluo@163.com
}

Keywords: Cultural Industry Cluster, Cultural Heritage, the Pearl River Delta.

\begin{abstract}
Cultural industries are potential emerging industries in the 21 st century. Historical and cultural heritage in Guangdong province are concentrated on the Pearl River Delta. The paper explains the foundation of development cultural industry cluster in the Pearl River Delta form demand, manufacture and industry chain. It conceives a new way to realize cultural heritage protection and economic development through developing cultural leading industries, forming cultural industry chain and establishing cultural industry cluster.
\end{abstract}

\section{Introduction}

Cultural industry is regarded as industry with a great development in the 21 st century. It has become a pillar industry in many developed countries. The development of cultural industry has gradually become an important strategy to many countries [1]. In 2012, the 18th National Congress of the Communist Party of China put forward the grand goal of culture industry become a pillar industry of national economy, cultural construction and foundation more solid in socialism. According to China's "cultural and related industry classification (2012)", culture and related industry is divided into 10 broad categories, 50 middle categories, 120 minimal categories. The protection of cultural heritage and intangible cultural heritage belongs to the cultural products, which belongs to the culture and art service.

The paper explains the foundation of development cultural industry cluster in the Pearl River Delta that is resource and labor advantage, cultural demand and industry chain. It conceives a new way to establish cultural industry cluster in the Pearl River Delta and provides a new method for the protection of historical architectural heritage.

\section{Basic Condition of the Development of Cultural Industry Cluster in the Pearl River Delta}

Cultural industry cluster is a lot of cultural industry enterprises and supporting institutions (including research institutes) that are closely related to each other gather in space through cooperation and sustainable competitive advantage in the cultural industry [2]. The condition of cultural industry cluster is cultural product consumption group, leading and related industry, cultural enterprises, high-quality talents etc... The formation motivation of industrial clusters can be divided into internal location and external implantation. For an area of rich cultural resources, the development of cultural industry has its innate advantages.

\section{Cultural Heritage Resources}

Guangdong province is one of the major cultural heritage resources in China. The Pearl River Delta is not only the economic core of Guangdong province but also the concentrated area of historical and cultural heritage. Guangdong province has 6 national historical and cultural cities among which are 3 cities located in the Pearl River Delta. China started on the selection activities of historic towns and villages in 2003.So far 528 national historic towns and villages were selected by the ministry of housing and the state bureau of cultural relics. There are 37 national historic towns and villages in Guangdong province among which are 21 in the Pearl River Delta as shown in Fig.1. There are 130 protected national heritages in Guangdong province among which are 68 in the Pearl River Delta. There are 520 provincial 
heritages and more than 2000 municipal heritages in Guangdong province. Most of them are located in the Pearl River Delta.

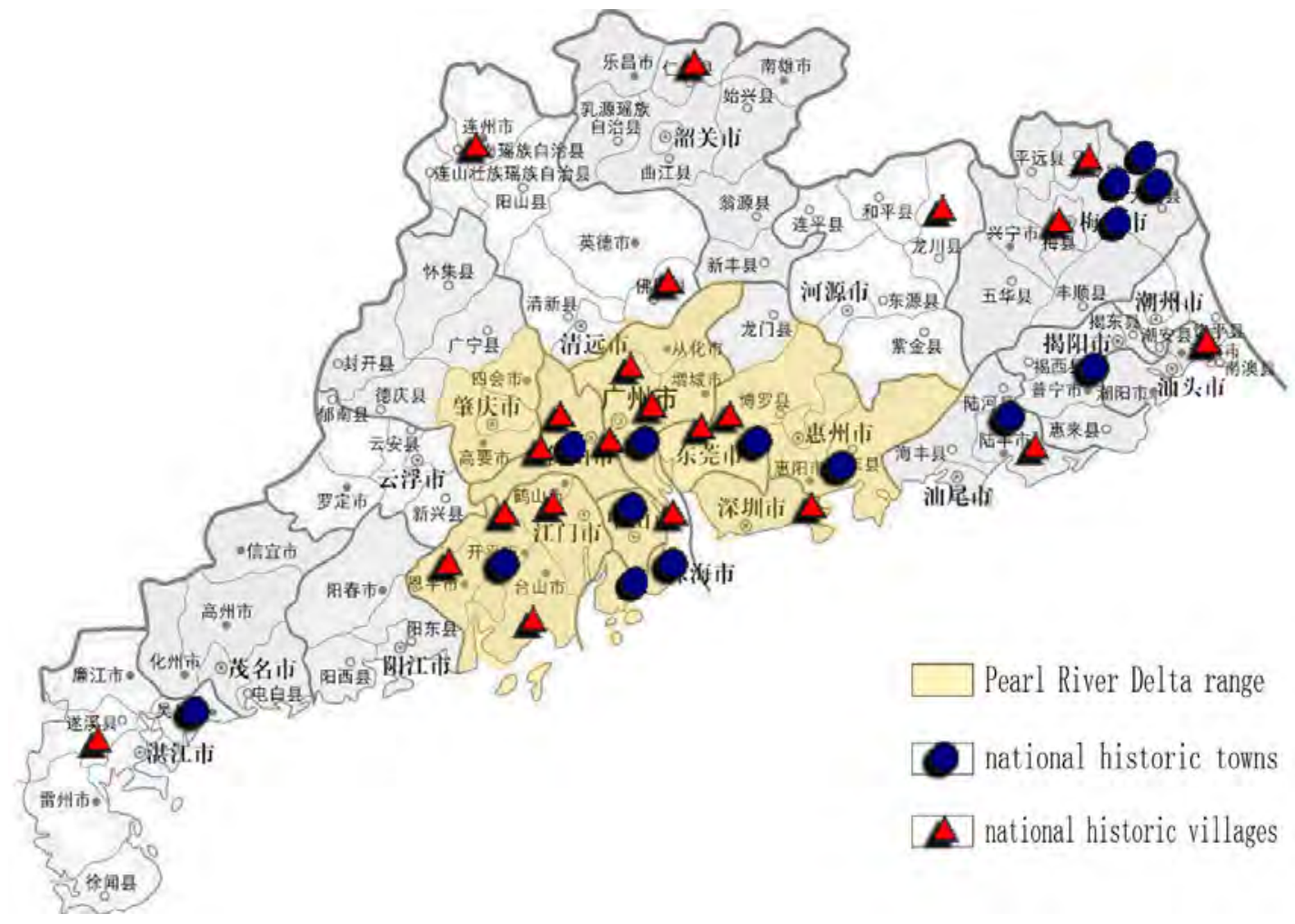

Fig.1 Location of National Historic Towns and Villages in Guangdong Province

\section{Advantage of Labor Force}

According to the traditional location theory the important factors of industry location is the geographical distribution of quantity and quality of labor. Culture industries depend on creativity which is the key to success. That means the labor of culture industries is high quality talents with innovative thinking. Many labor force of high quality gathered in the Pearl River Delta because of its' superior region and transportation conditions, social environment of open innovation and good living conditions. Distribution in or around the Pearl River Delta is the only way to access such labor market which strengthen the industry agglomeration.

\section{Cultural Demand}

According to the economic geography theory the influencing factors of industry space include demand, factors of production (labor, capital and information) and associated industries etc....Maslow put forward that the human demands can be divided into five levels, namely the physiological demand, safety demand, social demand, esteem demand and self actualization demand. Culture demand is a higher level of demand. With the income level of people improved cultural industry rose in the industrial revolution in order to satisfy people's spiritual demands [3]. Because of economy developed and residents of higher income of the Pearl River Delta the cultural production and cultural demands capacity are much higher than other underdeveloped area. Culture demand that goes beyond the physical demand prompted the intact preservation of historic towns and villages.

\section{Industry Chain}

The development of cultural industry cluster needs not only a large number of high-quality talents, but also abundant capital support and relative concentration of culture industry. The existing cultural industries have good foundation in the Pearl River Delta such as television and films industry, theatrical performance industry, travel services industry, exhibition services industry news industry, books and newspaper publishing industry as well as broadcasting industry etc...Therefore development of cultural 
industry cluster in the Pearl River Delta has its' innate advantages. Once the culture industry clusters will form and faster develop in the allocation of resources, scale, technical cooperation, talent aggregation and other aspects which in turn can make historical and cultural heritage better protection and utilization.

\section{Approach to Construct the Cultural Industry Cluster in the Pearl River Delta}

\section{Develop Suitable Leading Industry and Increase Employment Opportunities}

Cultural heritage in the Pearl River Delta widespread undergo aging and hollow phenomenon which is not conducive to the protection of cultural heritage. The key to solve the problem is increase employment opportunities and enhance the attractiveness of the community. The culture industry is like a huge employment "reservoir" which not only can increase the added value of culture but also can cause the change of industrial structure and employment structure [4]. This requires cultural heritage must have its own leading industries which has competition ability in the region. Only in this way can not only satisfy the local residents' employment requirements, but also attract a number of foreign populations and restore popularity and vitality of cultural heritage.

The development of leading industry can learn from the mode of town center. The choice of a leading industry that root in region with strong association and market expansion can through urban and rural planning according to local conditions, market demand and supply factors etc... [5].Specifically in the Pearl River Delta cultural heritage should develop cultural tourism, agriculture, culture and creative industry, film and television industry etc...For example the development of cultural tourism industry should implement the ecological restaurant, eco-lodges and ecological transportation which reduce the damage to the natural and human environment as far as possible. The development of cultural and creative industries can invigorate the cultural heritage and resources through the media, radio and television, music and books etc...

\section{Use Culture Resources and Form Cultural Industry Chain}

Under the condition of market economy people experience cross-culture with the improvement of the way of living and economic income. Cultural heritage can be regarded as economic resources used for the development of cultural industry to play the role of education and inheritance spirit civilization. But as a kind of special resources, cultural heritage is unique, public and non renewable. So we should pay attention to the protection of cultural heritage in the development of cultural industry.

In the long history of development the Pearl River Delta not only created a lot of material cultural heritage but also created a wealth of intangible cultural heritage, including a variety of folk music, folk dance, traditional opera, folk art and traditional handicrafts etc... Historic towns and villages in the Pearl River Delta are combination of material cultural heritage and intangible cultural heritage. They contain traditional architectural culture, live culture, food culture, clothing culture, marriage culture, funeral culture and clan culture etc...They are the historical resources with originality and uniqueness. The development of audio-visual, film and television, catering as well as research by use of these cultural resources around the leading industry not only can make the contradiction between protection and development as a driving force but also make them promote and complement each other.

\section{Focus on Cultural Heritage Advantages and Establish Cultural Industry Cluster}

Culture of the regional pattern is the derivatives interacted by administrative space system and structure of economy space. Use of the economic advantage, policy advantage, talent advantage and cultural advantages in the Pearl River Delta to establish the cultural industry cluster is a way to promote the effective protection of the cultural heritage and regional economic prosperity.

We analyze the national historic town Shawan Town as an example to explain Shawan cultural industry cluster. The town is located in Guangzhou city. It has 800 years of profound history and culture. It has unique geographical advantage of rivers and lakes in southern region. Shawan Town of ancient commercial prosperity gave birth to the unique local flavor of Cantonese culture and became one of the well-known towns in the Pearl River Delta far and near. The traditional culture resources in Shawan Town in the past have not been fully developed and utilized. In recent years Shawan Town seize the 
opportunity of "south land" in Guangzhou city and the 2010 "Asian Games" to make full use of rich and profound historical and cultural resources, good regional environment and convenient transportation to develop cultural industry as the leading industry. Under the vigorous promote by government agencies and market competition Shawan Town develop the real estate, tourism, commerce and trade service as the focus third industry through the historical and cultural resources. It promote the development of news, audio and video products, cultural performances, television and film as well as catering, tourism, advertising, exhibition and other chain industry as the theme of traditional and cultural heritage. It forms the scale effect and aggregation effect of cultural industry and ultimately forms the Shawan cultural industry cluster as shown in Fig.2.

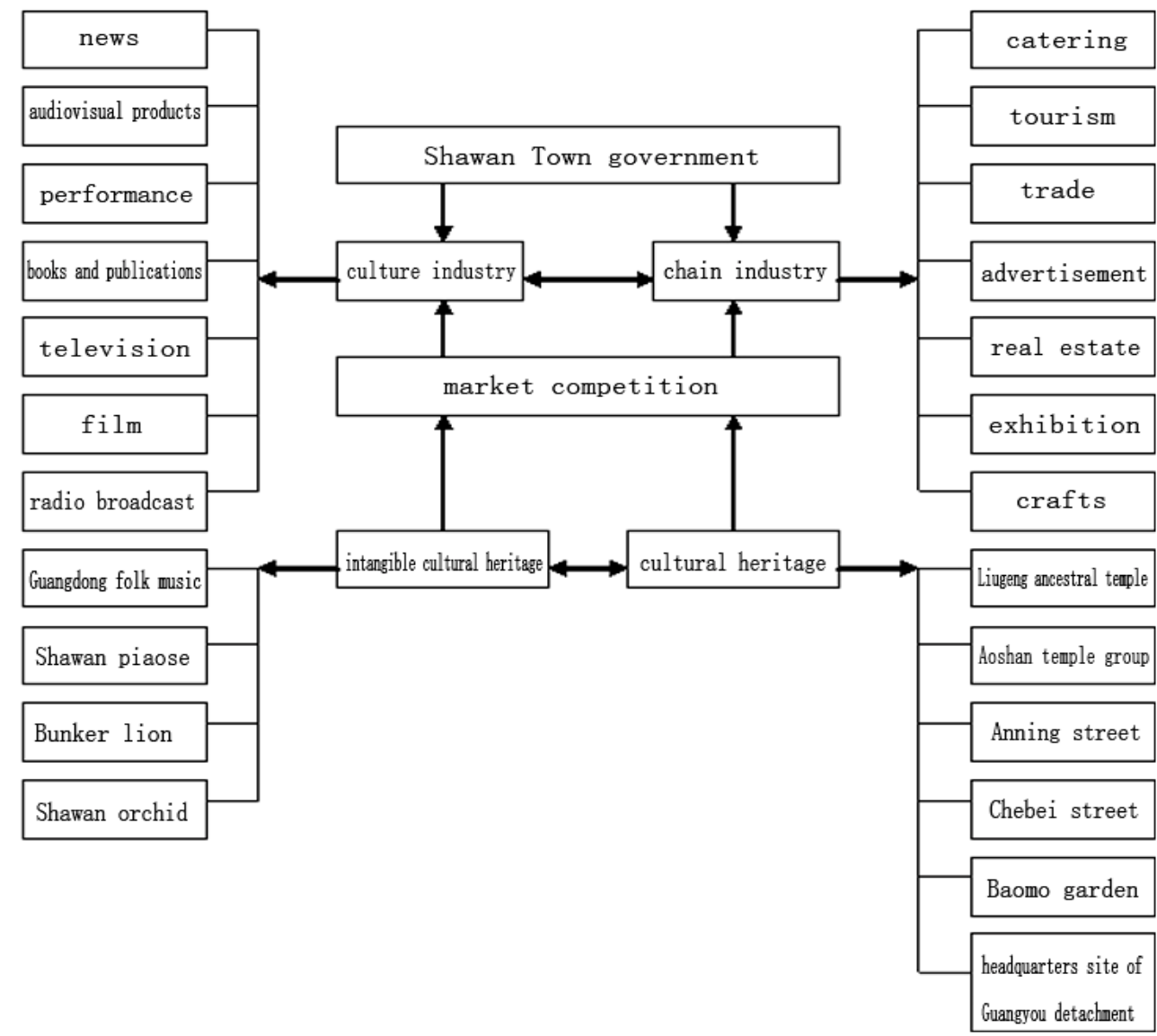

Fig. 2 Culture Industry Cluster in Shawan Town

\section{Summary}

With China's urbanization push forward continuously many cultural heritage will be affected by the economic impact. So how to coordinate the contradiction between protection and development is an urgent problem to be solved. The paper puts forward a positive thinking and exploring to build cultural industry clusters in the cultural heritage under the background of global actively cultivation of cultural industry. It aims to provide a win-win way to cultural protection and economic development.

\section{Acknowledgement}

This research was financially supported by the Scientific Research Foundation of Dongguan University of Technology (ZJ120301) and Teaching Research Foundation (E1365108).

\section{References}

[1]Xiaoli Jiang: China Culture Industry under the Background of Globalization, Sichuan University Press, Chengdu, 2006. 
[2]Xiaoming Kang, Xiang Yong, Industrial Cluster and the Promotion of Cultural Industry Competitiveness, Journal of Peking University. 2(2005)17-21.

[3]Liu Wei: Research on the Formation Mechanism of Cultural Industry Cluster, Doctoral Dissertation of Jinan University, Guangzhou, 2007.

[4]Zuhe Lu: Development Strategy of Cultural Industry, Social Sciences Academic Press, Peking, 2006.

[5]Yubin Luo, Influence of Industrial Clusters on Development of Central Towns in the Pearl River Delta, City Planning. 32(2008)75-78. 